\section{YIP vs. NIH}

\section{To the editor:}

As you know, our member companies are supporting and interested in the development of the EC-funded BRIDGE/ BIOTECH programmes, "Yeast Genome Sequencing Project."

Recent attempts by the NIH in the U.S. to file patent applications on DNA sequences made us very concerned about possible discrepancies between the interpretation of patent legislations in the various economic regions, and more specifically between the EC and the U.S. The definition of what is and what is not patentable needs harmonization.

DNA sequences (such as the ones discovered in the framework of the EC programmes) are being made available by scientists and "public domain." In our view, sequences of DNA fragments as such do not need patent protection, unless useful and industrially applicable incorporation of such sequences into new products can be demonstrated.

In addition to such legal and economic arguments, we believe it is important that such a distinction between "inventions" and "discoveries" is communicated to the public, and to Members of the European Parliament who will be discussing the proposed EC Directive on the Protection of Biotechnological Inventions. We believe it is important to avoid further misunderstandings and fears that industries will get direct property "on nature": this perception could be reinforced by granting patents on sequences "as such."

We can also report that the European scientists involved in the implementation of the "Yeast Genome Sequencing Project" share our views on this subject.

We hope the position of the $\mathrm{NIH}$ will evolve towards a more realistic and reasonable one in the near future, and appreciate any effort toward this goal by EC representatives in the EC-U.S. discussions on the subject, aswell as any attempt to improve public perception of this matter.

Matti Korhola

Yeast Industry Platform c/o A.M. Prieels

Avenue de l'Observatoire, 2 1180 Brussels, Belgium

\section{AIDS Awareness}

\section{To the editor:}

I wish to provide evidence in support of two comments made in Stephen Edgington's article "Is an AIDS Vaccine Possible?" (Bio/Technology10:768, July). The first is a quote from Stephen Berman: "The diversity of the virus is proportional to its time in the population." While it has been reported that there are five families of HIV worldwide, the virus is diverse in the U.S.--the MN strain dominates 60-70 percent of those tested, but no individual strain accounts for more than five percent of the remainder, Berman says.

"Presently vaccine-makers blame this high viral mutation rate for the failure to produce a traditional vaccine," adds Edgington.

The second quote is in a box ("What's Wrong with AIDS Research?"), and is as follows: "If anyone dares voice a minority view, it is often shouted down. As a result, new concepts in AIDS research originating from less well-known investigators gain acceptance more slowly than in other scientific areas."

All very interesting, in view of the fact that five years ago this month we submitted two very shorts papers, one to Nature ("AIDS, Latency and Error Rates in RNA") and one to New Scientist ("AIDS-An Error Catastrophe") - the latter as a direct response to an article in New Scientist by Christopher Boyce. Neither article was published, although many of the concepts we suggested in these articles have since been rediscovered (most notably in a long article in Science by a group from Oxford University). The notion of error catastrophe (as in some models of aging) still appears to be novel in the context of HIV research, however.

Will our views be "shouted down" again now, as suggested in Edgington's article in your journal?

\author{
Donald G. MacPhee \\ Department of \\ Microbiology \\ La Trobe University \\ Bundoora, Victoria \\ 3083 Australia
}

